\title{
Post-cancer treatment of Condurango 30C, traditionally used in homeopathy, ameliorates tissue damage and stimulates reactive oxygen species in benzo[a]pyrene-induced lung cancer of rat
}

\author{
Sourav Sikdar, Anisur Rahman Khuda-Bukhsh ${ }^{*}$ \\ Cytogenetics and Molecular Biology Laboratory, Department of Zoology, University of Kalyani, Kalyani-741235, India
}

\begin{abstract}
Homoeopathically prepared Condurango $30 \mathrm{C}$ is traditionally used in amelioration of certain types of cancer by homeopathic practitioners. In this study, ability of Condurango 30C in amelioration of the conventional benzo[a]pyrene $(\mathrm{BaP})$-induced lung cancer in rat has been tested. After one month of scheduled oral feeding of $\mathrm{BaP}$, lung cancer is routinely developed after four months in rats. Tumorbearing rats were then treated with Condurango $30 \mathrm{C}$ for the next one $\left(5^{\text {th }}\right)$, two $\left(6^{\text {th }}\right)$ and three $\left(7^{\text {th }}\right)$ months, respectively, and sacrificed. Efficacy of post-cancer treatment by Condurango 30C was evaluated against controls (placebo) by different study parameters like: body and lung weights, number and diameter of lung tumour nodules, lung architecture, DNA damage, anti-oxidant activity and reactive oxygen species (ROS) accumulation. Administration of this homeopathic remedy caused increase of body weight and decrease of lung weight, decrease in number and diameter of lung tumour nodules, particularly after one and two months of drug treatment. BaP intoxication significantly increased lipid peroxidase (LPO) with concomitant decrease in activities of different antioxidants, while Condurango 30C administration certainly reduce their levels than normal and cancerous groups, notably after one and two months' of drug treatment. Condurango 30C showed capability to induce ROS-mediated cell death evidenced from the study of ROS activities at different time-points. Further, the remedy possibly achieved its anticancer goal through mediation of DNA-nicks that possibly led cancer cells to the apoptotic pathway. Thus, Condurango $30 \mathrm{C}$ has anticancer potential in BaP-induced lung cancer of rats via tissue damage recovery and ROS-mediated programmed cell death.
\end{abstract}

Keywords lung cancer, benzo[a]pyrene $(\mathrm{BaP})$, Condurango 30C, tissue damage repair, antioxidants, homeopathy

\section{INTRODUCTION}

Cancer is a major health problem throughout the world (Ferlay et al., 2010). The risk factors behind cancer are mainly due to constant changes in environment, life-style and dietary habits (Kaur et al., 2009). In 2008, International Agency for Cancer Research has reported approximately 12.7 million new cancer cases and 7.6 million cancer deaths to have occurred, especially in the under-developed regions (Baliga, 2011). Among different types of cancer, lung cancer was placed at second position in 2009 (Department of Health, 2009; Hsu, et al., 2011). In the United States, over 215,000 new lung cancer cases are reported each year resulting in over 160,000 deaths annually (American Cancer Society, 2011). 85\% of lung cancer is non-small cell lung cancer (NSCLC), a heterogenous group comprised of mostly squamous cell carcinoma and adenocarcinoma (Bishop, et al., 2010). Cigarette smoking is the primary cause of lung cancer and lung inflammatory diseases. Benzo[a]pyrene (BaP) is one of the most well studied polycyclic aromatic hydrocarbons (PAHs) commonly found in cigarette smoke,

*Correspondence: Anisur Rahman Khuda-Bukhsh

E-mail: prof_arkb@yahoo.co.in; khudabukhsh_48@rediffmail.com

Received June 13, 2013; Accepted August 16, 2013; Published

August 31, 2013

doi: http://dx.doi.org/10.5667/tang.2013.0015

C 2013 by Association of Humanitas Medicine which is responsible for inducing lung tumour and inflammation in smokers (Harvey 1991). BaP is metabolized to ( \pm )-B[a]P-r-7,t-8-dihydrodiol-t-9,10-epoxide (BPDE), that binds to the exocyclic nitrogen of deoxyguanosine in DNA via trans-addition of the $\mathrm{C}-10$ position in the epoxide molecule and causes lung carcinogenesis (Sticha, 2000).

Surgical resection, radiation, or systematic chemotherapies are the main line treatments against lung cancer; but these often provide only temporary relief, and that too at the cost of damaging normal cells (Taraphdar et al., 2001). Therefore, search for drugs and/or agents that can inhibit lung cancer progression with no or little side-effects are continuing in different systems of medicine. Complementary and alternative medicines (CAMs) are among the most sought after disciplines to provide rich sources of effective anti-cancer drugs (Cheng et al., 2005). CAM therapies include homeopathy, mind-body interventions, dietary supplements, herbal products, and different traditional medicines etc., which are relatively safe and without any hazardous side-effects, and at a low cost (Yates et al., 2005). However, these CAM therapies need validation, particularly for their effect and proper dose. Amongst CAMs, many homeopathic mother tinctures and their potentized forms are being used as major alternative therapies against various diseases including cancer. Although the mother tinctures, which mainly are alcoholic extracts of some medicinal plants, are used without much inhibition for their possible effects, the 
potentized forms which are prepared by dilutions and succussions in a stepwise manner, often reach such a high dilution (beyond Avogadro's limit when the potency is $12 \mathrm{C}$ or above, see Khuda-Bukhsh, 2003 for detailed homeopathic dilution procedure) that the solution no longer is expected to contain even a single molecule of the original drug substance. So legitimate questions are asked whether such ultra-highly diluted remedies can actually affect the recovery process and if they do, how can they do so. However, efforts are on to find out if the highly diluted homeopathic remedies can trigger recovery responses and can alter quantifiable parameters of study, and that too in a repeatable manner. In fact, one of the main objectives of the present study is to explore whether, Condurango $30 \mathrm{C}$, diluted $10^{60}$ times, much beyond Avogadro's limit, can demonstrate clear evidences of its anti-cancer modulating abilities that can trigger initiation of the recovery process and can cause amelioration of the disease symptoms. Anticancer potential of several ultra-highly diluted homeopathic remedies has already been reported, as for example, Ruta graveolens 200C, Hydrastis 200C, Thuja 1M in tumour bearing animal models (ES et al., 2007), Chelidonium $30 \mathrm{C}$ and Lycopodium 30C in hepato-carcinogenic mice (Biswas et al., 2004; Pathak et al., 2006), Lycopodium 15C and 5C (Samadder et al, 2013) etc.

Marsdenia condurango (commonly called Condurango) is a major herb, belonging to Ascleplidaceae family and native to north-western part of South America. The bark extract of Condurango is commonly used in traditional system of medicine against stomach and digestive problems. It is also used to relieve from nausea and vomiting, stomach pain, cramps, gastric ulcers, and to increase bile in the gallbladder, liver and pancreas. Condurango was first introduced into the United States in 1871 with official certificates by doctors attesting to its ability to treat stomach cancer and syphilis (Tropical plant database. Database file for Marsdenia Condurango. www.rain-tree.com). According to Banerjee et al. (2008) Condurango in its different homeopathic forms are occasionally used against oesophageal and stomach cancer. But the efficacy of Condurango and its potentized forms had not been tested earlier against neoplastic lung cancer, although we (Sikdar et al., 2013) reported earlier the anticancer efficacy of Condurango mother tincture (crude extract) against non-small cell lung cancer, in vitro. As it is impracticable to test the efficacy of the potentized remedy in a controlled human study, the best possible manner through which such study could be executed was to examine and evaluate the effects of Condurango $30 \mathrm{C}$ in an induced lung cancer model of rat by chronic treatment of BaP.

Therefore, the major hypotheses to be tested in the study were : i) whether Condurango 30C could elicit favourable responses in BaP-induced lung cancer in respect of many established parameters of study like tissue damage repair in lung, regression of tumor nodules in size and number, as compared to control (placebo fed) rats; ii) if it did, to evaluate its responses in several other quantifiable parameters like lung weight, body weight, lung morphology, antioxidant activities including reactive oxygen generation (ROS) etc.

\section{MATERIALS AND METHODS}

\section{Chemicals and reagents}

Condurango 30C was bought from Schwabe India Pvt. Ltd. (India). Roswell Park Memorial Institute-1640 (RPMI-1640), fetal bovine serum (FBS) were purchased from Gibco BRL (Grand Island, NY, USA). Benzo[a]pyrene (BaP), 4',6-
Diamidino-2-phenylindole dihydrochloride (DAPI), dichlorodihydrofluorescein diacetate $\left(\mathrm{H}_{2}\right.$ DCFDA) and all other chemicals used were purchased from Sigma Chemical Co. (St. Louis, MO, USA).

\section{Experimental animals}

Inbred healthy white rats (Rattus norvegicus) weighing between $80 \mathrm{~g}$ and $90 \mathrm{~g}$ were reared in the animal house of the Department of Zoology, Kalyani University, West Bengal, India Ethical clearance for the experimental set up was obtained from the Institutional Ethical Committee, University of Kalyani. Animals were maintained under proper hygienic condition in polypropylene cages (temperature, $24 \pm 2^{\circ} \mathrm{C}$; humidity, $55 \pm 5 \%$, $12 \mathrm{~h}$ light/dark cycles), were allowed free drinking water and basal diet ad libitum, as per the guidelines of the Animal Welfare Committee, Department of Zoology, University of Kalyani.

\section{Study design}

A randomized set of forty two (42) rats were used for each time-point. Each set of 42 rats were again sub-divided into seven (7) different groups consisting of six (6) rats in each group, as stated below:

Group 1: Normal (Control 1): animals received food and water ad libitum, without any supplementation.

Group 2: Olive oil fed (Control 2): normal food and water, supplemented with olive oil (solvent of $\mathrm{BaP}$ ).

Group 3: Only placebo fed (Control 3): normal animals receiving drug vehicle ( $30 \%$ ethyl alcohol as placebo), orally once daily for 1,2 and 3 months, respectively, after four months of feeding normal diet and water.

Group 4: Only Condurango 30C treated (Control 4): normal animals receiving Condurango $30 \mathrm{C}$ orally once daily for 1,2 and 3 months, respectively, after four months of feeding normal diet and water.

Group 5: BaP treated (BaP fed) (Control 5): animals receiving $\mathrm{BaP}$ orally, 2 days (Tuesday and Friday) a week for 1 month and then normal diet and water.

Group 6: $\mathrm{BaP}+$ placebo treated (Control 6): animals receiving placebo orally once daily for 1,2 and 3 months, respectively, after development of lung cancer.

Group 7: $\mathrm{BaP}+$ Condurango 30C treated (Control 7): animals receiving Condurango $30 \mathrm{C}$ orally once daily for 1,2 and 3 months, respectively, after development of lung cancer.

The experimental data were collected by sacrificing the rats by spinal dislocation after $1\left(5^{\text {th }}\right), 2\left(6^{\text {th }}\right)$ and $3\left(7^{\text {th }}\right)$ months for analysis.

\section{Feeding of BaP}

$\mathrm{BaP}$ (dissolved in olive oil) at the dose of $50 \mathrm{mg} / \mathrm{kg}$ body weight was fed to each rat with the aid of pipette through gavage (Paul et al., 2011) twice a week for the first one month and kept for the next three months on only normal diet.

Preparation and administration of Condurango 30C

Condurango 30C, prepared as per the homeopathic principle of succussion and dilution. $1 \mathrm{ml}$ of Condurango $30 \mathrm{C}$ was diluted separately with $20 \mathrm{ml}$ of double distilled water to make the stock solution. Each rat was fed $0.06 \mathrm{ml}(60 \mu \mathrm{l})$ of Condurango $30 \mathrm{C}$ orally from the stock solution at a time with the aid of fine pipette (Biswas et al., 2002).

\section{Animal weights and lung weights}

The animals under experiment were weighted before and after carcinogenesis and drug treatment. Animal body weights and lung weights were measured at $5^{\text {th }}, 6^{\text {th }}$ and $7^{\text {th }}$ month timepoints. 
(A)

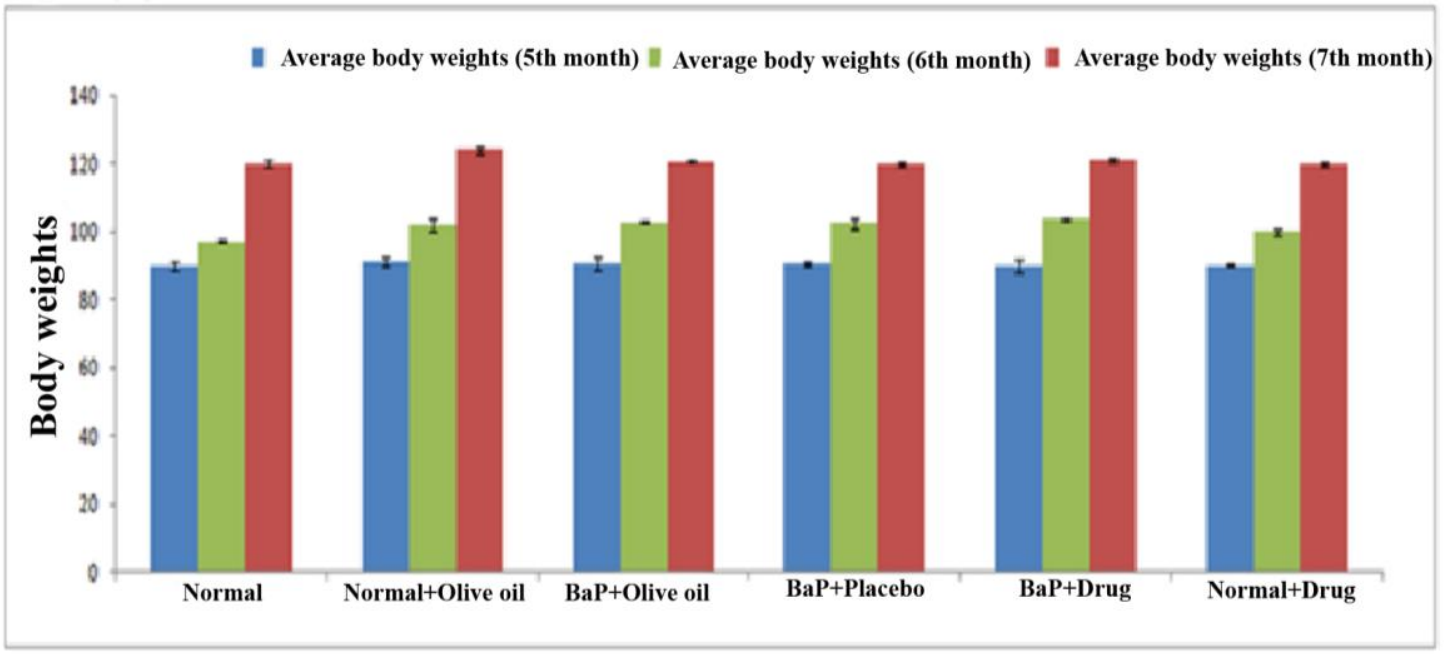

(B)

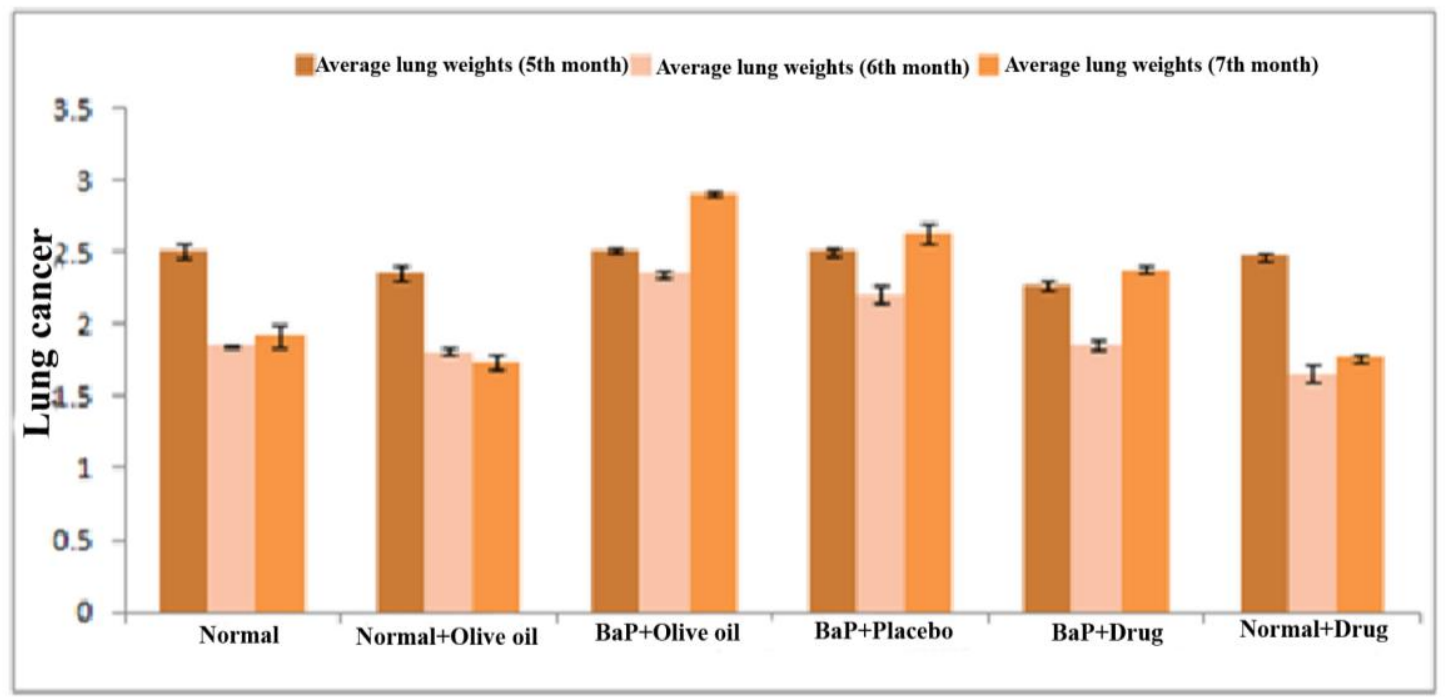

Fig. 1. Average differences in body weights and lung weights of rats at three month intervals. (A,B) Body weights of rats were barely discernible and lung weights were increased gradually in cancer-bearing (BaP-treated) and BaP+placebo treated rats, as compared to that of normal at each interval. But in case of drug treated rats, body weights increased and lung weights decreased very little at each interval, but not significant change was found when compared between the BaP-treated Condurango 30C fed and unfed groups in different time points studied, except the significance level regarding lung weights between normal and $\mathrm{BaP}-$-fed cancer groups at $6^{\text {th }}$ and $7^{\text {th }}$ month intervals and between cancer and $\mathrm{BaP}+\mathrm{drug}$ treated groups at $5^{\text {th }}, 6^{\text {th }}$ and $7^{\text {th }}$ month intervals. When the body weights and lung weights of rats of only drug fed and only placebo fed rats were compared, they appeared not much different from that of the normal ones without any supplementation.

\section{Lung morphology with tumour nodule number and diameter measurement}

Lung morphologies of cancerous and drug treated rats were observed, and the number of each tumour nodules were noted down properly at $5^{\text {th }}, 6^{\text {th }}$ and $7^{\text {th }}$ month intervals of both cancerous and drug treated groups. The diameter of each visible tumour was measured in centimetre $(\mathrm{cm})$ with the aid of a $\mathrm{cm}$ scale placed by the side of each lung tissue.

\section{Preparation of lung and liver tissue homogenates}

Lung and liver tissues were homogenized after dissolving them in protein lysis buffer according to the method followed by Chakraborty et al. (2012). The total protein content was measured by Bradford method using crystalline bovine serum albumen as control (Bradford, 1976).

\section{Biochemical analysis of various enzymatic parameters}

The activities of lipid peroxidase (LPO) (Kamaraj et al., 2009), catalase (CAT) (Aebi, 1984), superoxide dismutase (SOD) (Fridovich, 1989) and reduced glutathione (GSH) (Morin et al., 1978) from lung tissue homogenates were spectrophotometrically analysed according to Chakroborty et al., (2012). Aspertate amino transferase (AST) and alanine amino transferase (ALT) levels of liver tissue homogenates were also analysed spectroscopically according to Stanton et al., (2005).

\section{Lung cell perfusion}

Lungs were dissected out quickly from each rat under experiment and washed with phosphate buffer saline (PBS). Then the tissues were minced into small pieces within $2 \%$ RPMI-1640 media and the lung epithelial cells were flushed out gently in the media with the aid of hypodermic syringe. The 
Table 1. Effect of Condurango 30C on rat

\begin{tabular}{lcccc}
\hline & Control & $\begin{array}{c}\text { Condurango 30C treated } \\
\left(\mathbf{5}^{\text {th }} \text { month }\right)\end{array}$ & $\begin{array}{c}\text { Condurango 30C treated } \\
\left(\mathbf{6}^{\text {th }} \text { month }\right)\end{array}$ & $\begin{array}{c}\text { Condurango 30C treated } \\
\left(\mathbf{7}^{\text {th }} \text { month }\right)\end{array}$ \\
\hline ALT & $36.53 \pm 1.05$ & $33.53 \pm 2.87^{*}$ & $35.23 \pm 0.58$ & $35.46 \pm 0.057$ \\
AST & $17.40 \pm 0.043$ & $17.41 \pm 0.07$ & $17.42 \pm 0.06$ & $17.40 \pm 0.101$ \\
\hline
\end{tabular}

Data are expressed as mean $\pm \mathrm{SD}(\mathrm{n}=6) .{ }^{*} p<0.05$ vs. normal control group.

media containing cells were passed through a thin nylon mesh $(0.22 \mu \mathrm{m})$ and the cells were spinned down at 1,000 g for 3-4 min. The blood cells were pelleted out and the supernatant containing lung epithelial cells were used for further study (Kundu et al., 2009; Henneke et al., 2010).

\section{Study on intracellular ROS accumulation}

To evaluate the level of intracellular ROS accumulation, perfused live lung epithelial cells were incubated with $\mathrm{H}_{2}$ DCFDA $(20 \mu \mathrm{M})$ for $30 \mathrm{~min}$ at $37^{\circ} \mathrm{C}$ and the intensity of $\mathrm{H}_{2}$ DCFDA-fluorescence was determined by a flowcytometer (FACS Callibur; BD Bioscience) (Chakraborty et al., 2012).

\section{Determination of tissue architecture and DNA-nick generation}

Formalin-fixed lung tissue sections $(5 \mu \mathrm{m})$ were dehydrated with downgraded alcohols and stained with DAPI $(10 \mu \mathrm{g} / \mathrm{ml})$ for $30 \mathrm{~min}$ at $37^{\circ} \mathrm{C}$. Finally the tissue architecture and DNA damage were observed under a fluorescence microscope (Leica, Germany) (Kollinga et al., 2008).

\section{Statistical analysis}

Data were analyzed and significance of the differences between the mean values was determined by one-way analysis of variance (ANOVA) with LSD post hoc tests, using SPSS 14 software (SPSS Inc, Chicago, IL, USA). Statistical significance was considered at ${ }^{*} p<0.05$.

\section{RESULTS}

Analysis of liver damage by ALT-AST activity measurement The ALT-AST activity measurement is often done to check liver toxicity or damage. BaP treatment did not increase liver toxicity significantly. No significant changes were also found between $\mathrm{BaP}$ alone and $\mathrm{BaP}+$ placebo treated groups in respect of their ALT and AST activities (Table 1). There were also no significant differences of ALT, AST activities among normal, olive oil, placebo and Condurango $30 \mathrm{C}$ alone treated groups (data not shown). Therefore we excluded rats belonging to groups 2, 3, 4 and 6 from further in-depth studies.

\section{Animal and lung weight measurements}

Although decrease in the body weights (Fig. 1A) of the rats was not found to be so palpable, the gradual increase in lung weights (Fig. 1B) along with the lapse of time in both the BaP and $\mathrm{BaP}+$ placebo treated cancerous rats, could be quite discernible. Lung weights were increased gradually due to formation of tumour like nodules. But in case of drug treated rats, body weights increased and lung weights decreased; the degree of differences in weight was not very dramatic, but positive to some extent when compared between the $\mathrm{BaP}$ treated drug fed and unfed groups (i.e., $\mathrm{BaP}+$ placebo treated rats) in different time points studied. The graphical bar diagrams (Fig. 1A,B) of body weights and lung weights of rats, respectively, at each interval supported the data. Thus it is apparent that placebo treatment had no effect to inhibit cancer progression. When the body weights and lung weights of rats of only drug fed and only placebo fed rats were compared, they appeared not much difference from that of the normal ones (without any supplementation). Therefore only Condurango $30 \mathrm{C}$ treatment appeared to probably have positive ameliorating effects on the tumour growths, that could be reflected in the results of the data of the three time points studied.

\begin{abstract}
Determination of lung morphologies with measurement of lung tumour nodules and diameter

Tumour nodules in BaP-induced cancerous lungs were clearly visible at the $5^{\text {th }}$ and $6^{\text {th }}$ months, which on an average were two and six (Fig. 2A,B) in number and had mean diameter measurement values of $0.81 \pm 0.175 \mathrm{~cm}$ and $0.86 \pm 0.351 \mathrm{~cm}$, respectively. The lung structure, measuring nearly $4 \mathrm{~cm}$ in diameter (Fig. 2C), was found to be quite deformed with numerous tumours, overlapping with one another in $\mathrm{BaP}$ alone fed rats, at the $7^{\text {th }}$ month, making it absolutely difficult to count the number of tumours, for which the data on number of nodules at this time-point was not considered in the histogram. After drug treatment, particularly at the $5^{\text {th }}$ and $6^{\text {th }}$ month intervals (Fig. 2D,E), on an average one minute tumour nodule was observed, measuring $0.15 \pm 0.05 \mathrm{~cm}$ and $0.16 \pm 0.04 \mathrm{~cm}$, respectively, in diameter. But at the $7^{\text {th }}$ month of drug treatment, on an average, two tumour nodules were visible (Fig. 2F), which had an approximate mean diameter of $1.6 \pm 0.2 \mathrm{~cm}$. Fig. $2 \mathrm{G}$ and Fig. $2 \mathrm{H}$ represent graphically the average number of tumour nodules and tumour diameters, respectively, in rats, fed $\mathrm{BaP}$ only and $\mathrm{BaP}+\mathrm{drug}$, at the three time-points studied.
\end{abstract}

\section{Analysis of intracellular ROS accumulation}

Results indicated the gradual induction of ROS in $5^{\text {th }}$ and $6^{\text {th }}$ month intervals of post-cancerous Condurango 30C treatment in respect to normal and cancerous groups at $5^{\text {th }}$ and $6^{\text {th }}$ month intervals (Fig. 3). But at $7^{\text {th }}$ month interval of drug treatment

Table 2. Role of Condurango 30C on different anti-oxidant biomarkers with the LPO level in BaP-intoxicated cancerous lungs of rat

\begin{tabular}{|c|c|c|c|c|c|c|c|}
\hline & Control & C1 & $\mathrm{C2}$ & $\mathbf{C 3}$ & 30_1 & 30_2 & 30_3 \\
\hline $\begin{array}{c}\text { Catalase } \\
(\mu \mathrm{m} / \mathrm{mg} \text { protein })\end{array}$ & $14.76 \pm 0.89$ & $10.91 \pm 0.405$ & $9.09 \pm 0.5^{*}$ & $10.75 \pm 1.33$ & $7.79 \pm 4.77^{* \# @ \$}$ & $4.93 \pm 7.49^{* \# @ \$}$ & $13.59 \pm 4.94$ \\
\hline $\begin{array}{c}\text { GSH } \\
(\mu \mathrm{m} / \mathbf{m g} \text { protein })\end{array}$ & $0.078 \pm 0$ & - & $.155 \pm 0.0005^{* \#}$ & $0.092 \pm$ & $0.138 \pm 0.002^{* \text { *\#\$ }}$ & $0.091 \pm 0.0075^{* \# @ \$}$ & $0.159 \pm 0.004^{* \# @ \$}$ \\
\hline $\begin{array}{c}\text { SOD } \\
(\mu \mathrm{m} / \mathrm{mg} \text { protein })\end{array}$ & 4 & $2.41 \pm 0.041^{*}$ & $1.83 \pm 0.035^{*}$ & $1.94 \pm 0.14^{*}$ & $2.21 \pm 0.293^{* \# @ \$}$ & \$ $1.92 \pm 0.122^{* \# @ \$ ~}$ & $4.006 \pm 0.081^{* \# @ \$}$ \\
\hline $\begin{array}{c}\text { LPO } \\
(\mu \mathrm{m} / \mathrm{mg} \text { protein }) \\
\end{array}$ & $5.63 \pm 0.46$ & $7.11 \pm 0.42^{*}$ & $9.5 \pm 0.417^{* \#}$ & $14.33 \pm 0.28^{* \# @ ~}$ & $5.62 \pm 0.22^{\# @ \$}$ & $1.4 \pm 0.2^{* \# @ \$}$ & $9.73 \pm 1.301^{\text {*\# }}$ \\
\hline
\end{tabular}

[C1- Cancer ( $5^{\text {th }}$ month), C2- Cancer ( $6^{\text {th }}$ month), C3- Cancer ( $7^{\text {th }}$ month), 30_1- Condurango 30C treated (5 $5^{\text {th }}$ month), 30_2- Condurango 30C treated ( $6^{\text {th }}$ month), 30_3- Condurango 30C treated $\left(7^{\text {th }}\right.$ month)]. Data are expressed as mean $\pm \mathrm{SD}(\mathrm{n}=6) .{ }^{*} p<0.05$ vs. normal control group ${ }^{\#} p<0.05$ vs. BaP induced cancerous group $\left(5^{\text {th }}\right.$ month). ${ }^{@} p<0.05$ vs. BaP induced cancerous group $\left(6^{\text {th }}\right.$ month $) .{ }^{\$} p<0.05 \mathrm{vs}$. BaP induced cancerous group $\left(7^{\text {th }}\right.$ month). 


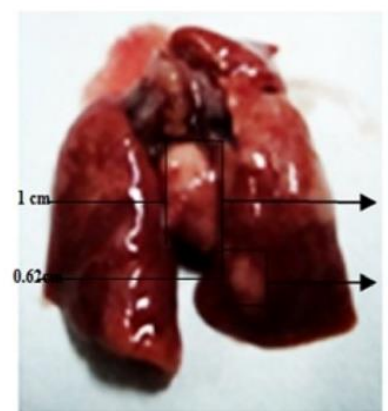

(A)

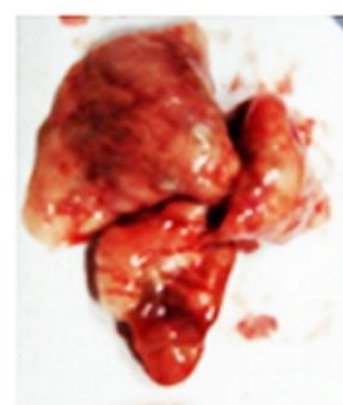

(D)
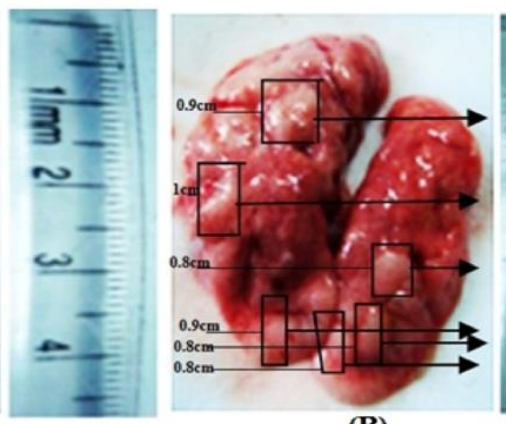

(B)

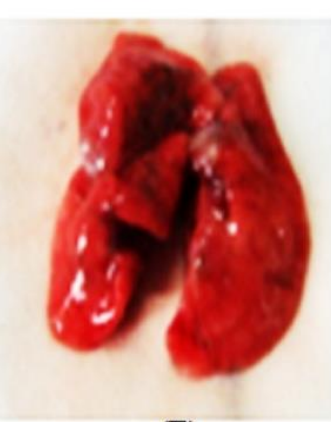

(E)
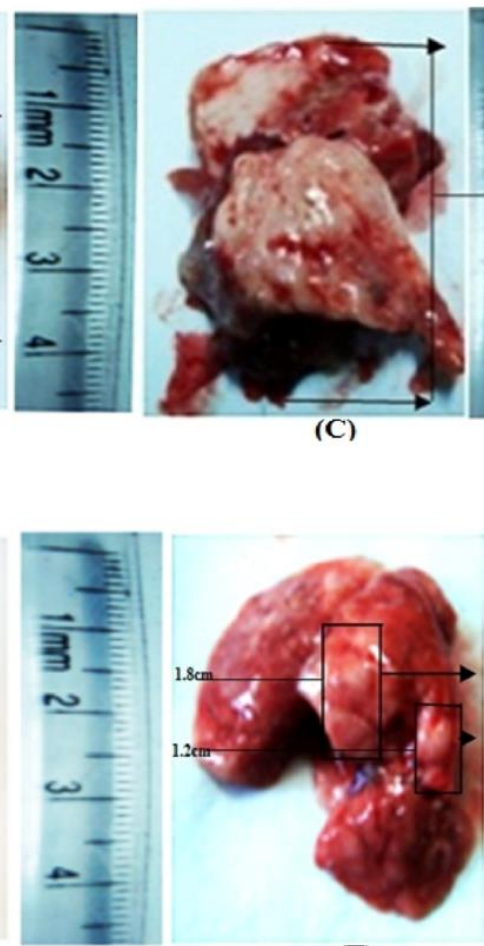

(F)

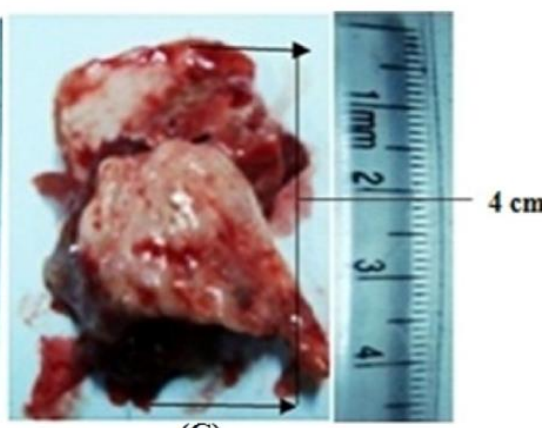

(C)

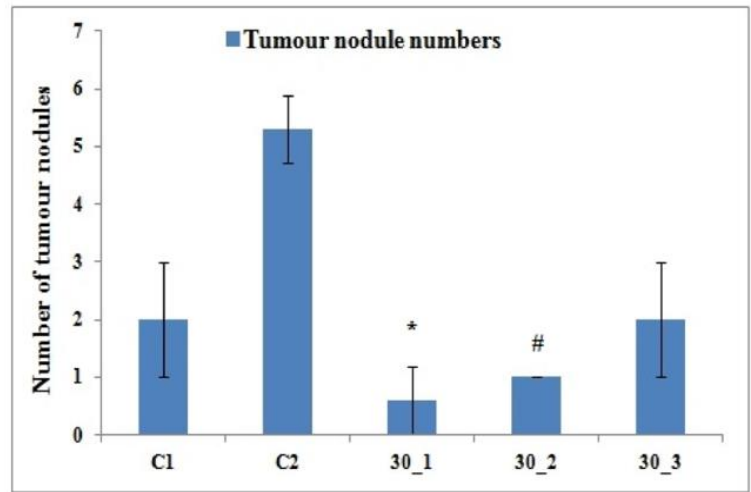

(G)

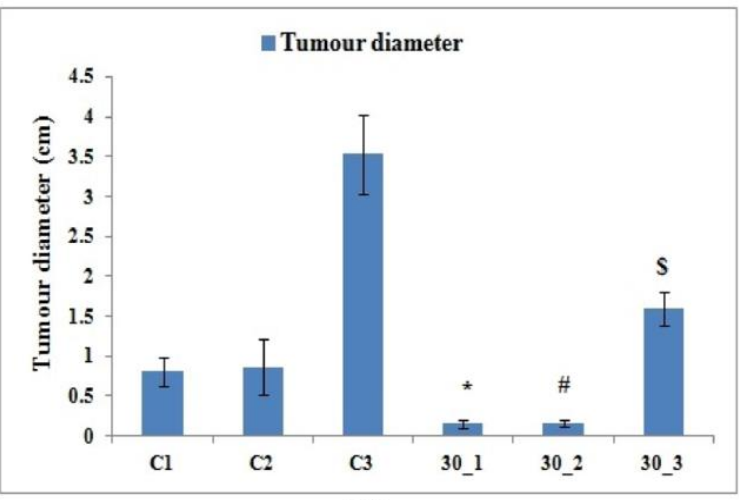

(H)

Fig. 2. Tumour number and diameter measurements. Data of number of tumour nodules and diameter of tumours after the $5^{\text {th }}, 6^{\text {th }}$ and $7^{\text {th }}$ months in $\mathrm{BaP}$ treated group (A, B and $\mathrm{C}$, respectively) as also in $\mathrm{BaP}+$ Condurango $30 \mathrm{C}$ treated groups (D, E and $\mathrm{F}$, respectively), the mean values with standard deviation and significance levels of the tumour nodules' numbers $(\mathrm{G})$ and tumour diameters $(\mathrm{cm})(\mathrm{H})$ are shown $(\mathrm{n}=6)$. Significance level ${ }^{*} p$ $<0.05$ denotes: cancer $(\mathrm{C} 1)$ vs Condurango 30C (30_1) treated at $5^{\text {th }}$ month interval and ${ }^{\#} p<0.05$ denotes: cancer (C2) vs Condurango 30C (30_2) at $6^{\text {th }}$ month interval, respectively. Since the whole lung was covered with numerous tumours overlapping one another (C), and not permitting accurate count, the data was not shown in $(\mathrm{G})$; the mean values with standard deviations of tumour diameters for the Condurango $30 \mathrm{C}$ treated and untreated groups are shown in $(\mathrm{H}),(\mathrm{n}=6)$. Significance ${ }^{*} p<0.05$ denotes: cancer $(\mathrm{C} 1)$ vs Condurango 30C treated $\left(30 \_1\right)$ at $5^{\text {th }}$ month intervals, ${ }^{\#} p<0.05$ denotes: cancer (C2) vs Condurango 30C treated (30_2) at $6^{\text {th }}$ month interval and ${ }^{s} p<0.05$ denotes cancer (C3) vs Condurango 30C (30_3) treated at $7^{\text {th }}$ month interval, respectively.

the ROS elevation became low indicate that at this time-point drug had lost the capacity to protect the oxidative stress due to uncontrolled cancer progression supported by the lung morphology at the last month interval.

\section{Biochemical analysis of lung homogenates}

A highly significant $(p<0.05)$ increase of LPO with concomitant decrease in the activity of enzymatic antioxidants (GSH, CAT, SOD) were observed in BaP-induced cancerous rats (Table 2). But LPO level and the antioxidative activities were found more decrease in Condurango 30C treated rats, especially at $5^{\text {th }}$ and $6^{\text {th }}$ month intervals than cancerous groups. These results signify that Condurango $30 \mathrm{C}$ has the capacity to inhibit cancer progression by reducing antioxidative activities via ROS accumulation to maintain oxidative balance in cancerous rat lungs, especially at $5^{\text {th }}$ and $6^{\text {th }}$ month intervals.

\section{Assessment of tissue architecture and DNA damage by DAPI staining}

In case of normal lung tissue section, we found no such DAPIfluorescence intensity due to absence of DNA-nick and the tissue architectures were well oriented with proper alveolar spaces. But in cancer-bearing groups $\left(5^{\text {th }}, 6^{\text {th }}\right.$ and $7^{\text {th }}$ month intervals), the lung sections were found to be distorted with gradually increased irregular and condensed alveolar spaces, an evidence of progression of lung cancer by BaP-intoxication. Furthermore, fluorescence by DAPI was of limited intensity in $\mathrm{BaP}$-treated groups due to absence of DNA nick or 


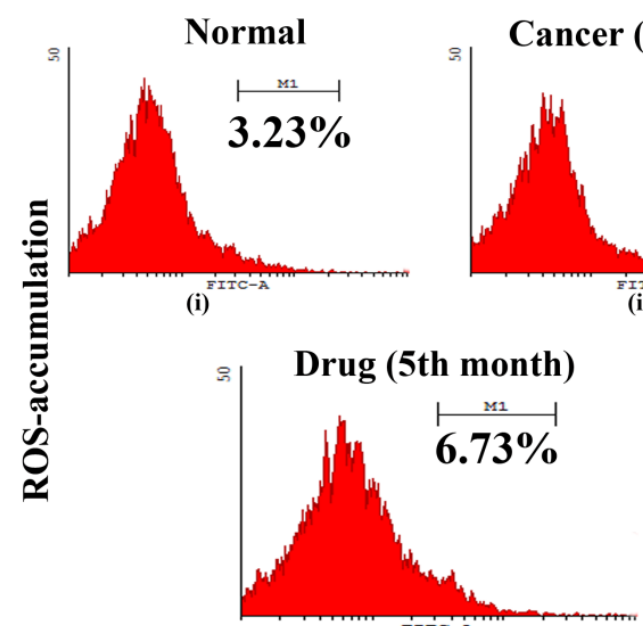

(v)

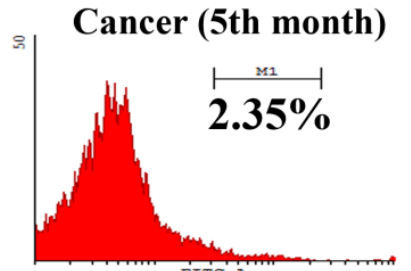

(ii)

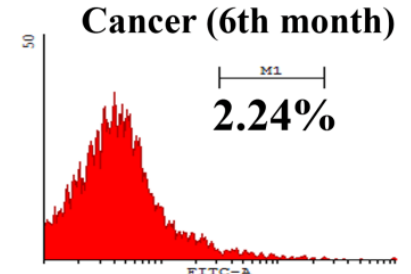

(iii)

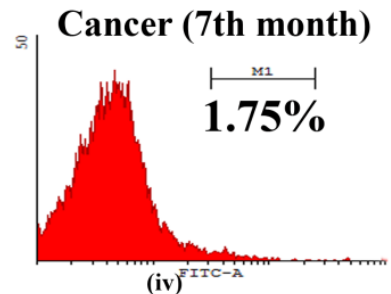

(iv)

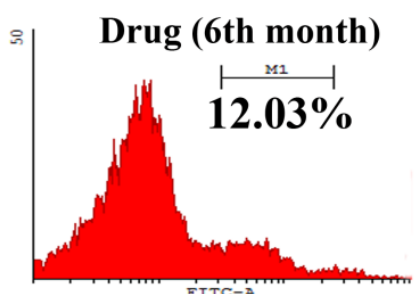

(vi)

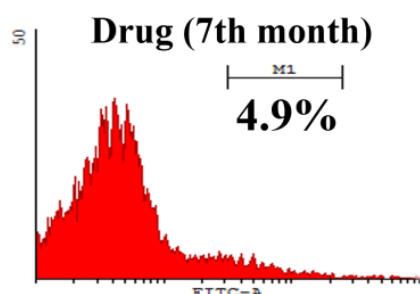

(vii)

Fig. 3. Estimation of ROS accumulation. The flow-cytometric data clearly showed the increase of mean fluorescence intensity of ROS accumulation at $5^{\text {th }}$ and $6^{\text {th }}$ month intervals of Condurango $30 \mathrm{C}$-fed groups in respect to normal, and BaP-induced cancerous groups $\left(5^{\text {th }}\right.$ and $6^{\text {th }}$ month intervals), suggesting thereby Condurango $30 \mathrm{C}$ has the capacity to induce ROS in post-cancerous lung, in vivo. But at the last or $7^{\text {th }}$ month interval of postcancerous drug treatment, the ROS production was little increased than normal and cancerous groups, but very much decreased in amount than $5^{\text {th }}$ and $6^{\text {th }}$ month intervals of drug treated groups, possibly signifying the inactivity of the drug to induce ROS for long term treatment. (i) normal group, (ii)(iv) cancer groups at $5^{\text {th }}, 6^{\text {th }}$ and $7^{\text {th }}$ months, respectively and (v)-(vii) drug fed groups at $5^{\text {th }}, 6^{\text {th }}$ and $7^{\text {th }}$ months, respectively.

fragmentation. On the other hand, intense DAPI-fluorescence was noticeable in the drug treated lung sections; the intensity increased gradually at $5^{\text {th }}$ and $6^{\text {th }}$ month intervals, due to formation of DNA nick or fragmentation triggered by Condurango 30C presumably due to apoptosis generation (Fig. 4). But at the $7^{\text {th }}$ month time-point, the intensity of fluorescence again became subdued, implying that the drug failed to sustain its effect long enough to inhibit cancer progression any more.

\section{DISCUSSION}

Results of the present study showed that Condurango 30C was able to ameliorate lung cancer after it had been induced by $\mathrm{BaP}$ treatment in rats. It could induce recovery of tissue damage and modulate activities of antioxidants via ROS generation in $\mathrm{BaP}$ intoxicated rats. Our earlier study (Paul et al., 2011) reported that $\mathrm{BaP}$ could induce lung cancer, specifically NSCLC, and in this study we have shown histological evidence of tissue recovery after Condurango 30C administration. Further, the number of nodules and the tumour diameter were reduced after the drug treatment. The study assumes further significance because after confirmed development of lung cancer, the drug was administered and showed its ameliorating ability in terms of positive changes in tissue architecture and other cancer biomarkers.

Antioxidant status has been suggested as a useful tool to

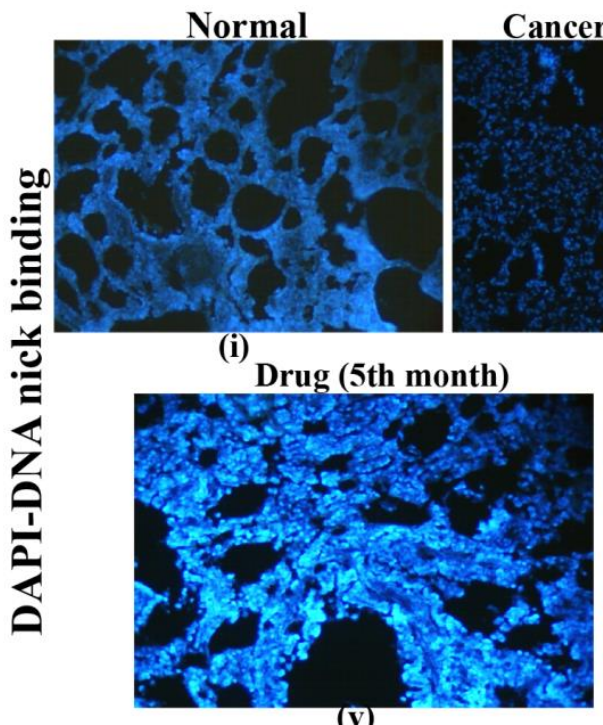

(v)

\section{Cancer (6th month)}

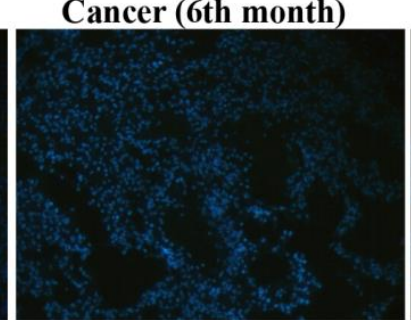

(ii)

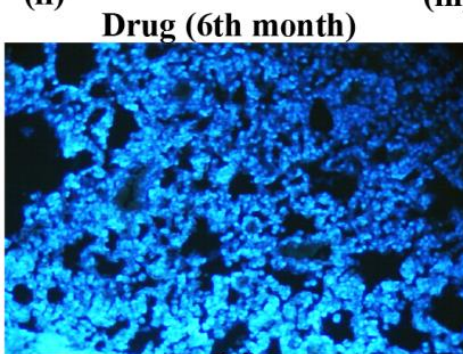

(vi)
Cancer (7th month)

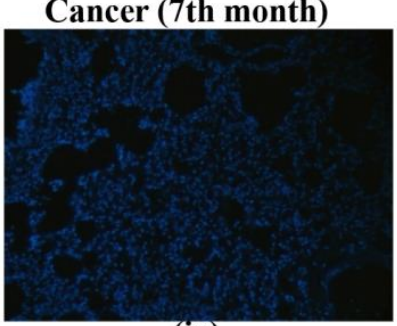

(iv)

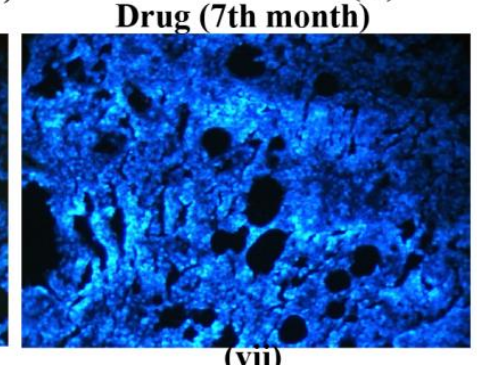

Fig. 4. Observations of lung tissue architecture and DNA-nick generation by DAPI-staining after Condurango 30C post-cancerous treatment. (i) Normal lung tissue section showed general tissue architectures and proper alveolar spaces with no such fluorescence intensity after DAPI staining. But in BaP-intoxicated cancerous groups $\left[5^{\text {th }}\right.$ (ii), $6^{\text {th }}$ (iii) and $7^{\text {th }}$ (iv) month intervals], the lung sections gradually showed tissue distortions with irregular and condensed alveolar spaces and DAPI gave fluorescence of lesser intensity due to absence of DNA nick or fragmentation due to carcinogenesis. But in Condurango 30C-treated groups, especially at $5^{\text {th }}(\mathrm{v})$ and $6^{\text {th }}(\mathrm{vi})$ month intervals, clear DNA nick formation was found as indicated by intense DAPI fluorescence, suggesting thereby the formation of DNA-fragmentation which possibly occurred by apoptosis induction in BaP-induced lung cancer of rat. But at the last month time-point (vii) of Condurango 30C treatment, DNA nick was less palpable which probably indicated the inability of the drug to inhibit long term lung cancer progression. 
estimate the risk of oxidative damage induced by carcinogen. One of the major reasons behind BaP-induced lung cancer is the depletion of antioxidant defence mechanism which is related to the reduction of anti-oxidative enzymes' activity including SOD, catalase and GSH (Kamaraj et al., 2009). These antioxidants can synergistically scavenge reactive oxygen species (ROS) and prevent LPO. SOD can disrupt superoxide radicals and protect the cells against superoxide and hydrogen peroxide-mediated LPO (Ekambaram et al., 2008). Several reports have recently been cited about decreased activities of SOD and catalase in various carcinogenic conditions (Kamaraj et al., 2009). Catalase is widely distributed in all tissues and is known to catalyse the breakdown of hydrogen peroxide produced by tumor cells. SOD, catalase and GSH constitute a group of defense against reactive oxygen species which have been found to be decreased in $\mathrm{BaP}$-induced lung cancer bearing animals (Kamaraj et al., 2007). Changes in the rate of cancer cell proliferation are accompanied by changes in their intracellular GSH levels and consequently these could be reflected in their antioxidant machineries. Increased levels of LPO play a major role in the early phases of tumor growth (Rice-Evans and Burdon, 1993). Decreased levels of LPO after Condurango $30 \mathrm{C}$ treatment could be attributed to its ability to modulate the levels of antioxidants. Our findings also indicate that the administration of Condurango $30 \mathrm{C}$ against BaPinduced lung carcinogenesis decreased the activities of antioxidants, especially at $5^{\text {th }}$ and $6^{\text {th }}$ month time-points. The flowcytometric data of ROS accumulation especially at $5^{\text {th }}$ and $6^{\text {th }}$ month time-points in Condurango $30 \mathrm{C}$ treated rats further suggest the ability of the drug to induce oxidative damage. But at the last month of treatment, the antioxidant levels were certainly increased supported by the decrease in ROS production made an indication that the drug fails to induce ROS mediated cell death for long term of post cancerous lung treatment.

One of the hallmarks of apoptosis mediated cell death is the internucleosomal DNA breakdown (Yeh and Yen, 2005). The results of DNA damage study by DAPI staining revealed the formation of DNA-nick or fragmentation which would suggest the ability of Condurango $30 \mathrm{C}$ to induce DNA damage via apoptosis generation, especially at the $5^{\text {th }}$ and $6^{\text {th }}$ month fixation intervals. Since Condurango $30 \mathrm{C}$ is unlikely to possess even a single molecule of the original drug substance, and yet demonstrated considerable anti-cancer effect in $\mathrm{BaP}$-induced lung cancer of rat, it is difficult to explain the molecular mechanism of action of this drug. However, the positive results will lend support to the hypothesis of Khuda-Bukhsh (KhudaBukhsh 2003, 2006, 2011; Mallick et al., 2003) who advocated that potentized homeopathic drugs could possibly act at the molecular level by triggering specific cascade of gene actions to remove disease symptoms. Further studies are warranted to validate the use of such ultra-high diluted remedies in other animal models, because these drugs can be more confidently used at least as a supportive remedy in cancer care.

\section{ACKNOWLEDGEMENTS}

The authors are grateful to Boiron Laboratories, Lyon, France for partial financial support of the work.

\section{CONFLICT OF INTEREST}

None to declare.

\section{REFERENCES}

Aebi H. Catalase in Vitro. In Methods in Enzymology, Packer L ed. (San Diego, USA: Academic Press), pp. 121-126, 1984.

American Cancer Society. Cancer reference Information. What are the key statistics about lung cancer? Available at: http://www.cancer.org (accessed on $01^{\text {st }}$ May 2013).

Baliga MS and Dsouza JJ. Amla (Emblica officinalis Gaertn), a wonder berry in the treatment and prevention of cancer. Eur $\mathbf{J}$ Cancer Prev. 2011;20:225-239.

Banerji P, Campbell DR, Banerji P. Cancer patients treated with the Banerji protocols utilising homoeopathic medicine: A Best Case Series Program of the National Cancer Institute USA. Oncol Rep. 2008:20:69-74.

Bishop JA, Benjamin H, Cholakh H, Chajut A, Clark DP, Westra WH. Accurate classification of non-small cell lung carcinoma using a novel microRNA-based approach. Clin Can Res. 2010;16:610-619.

Biswas SJ, Khuda-Bukhsh AR. Effect of a homeopathic drug, Chelidonium, in amelioration of p-DAB induced hepatocarcinogenesis in mice. BMC Complement Altern Med. 2002;2:1-12.

Biswas SJ and Khuda-Bukhsh AR. Evaluation of protective potentials of a potentized homeopathic drug, Chelidonium majus, during azo dye induced hepatocarcinogenesis in mice. Indian J Exp Biol. 2004;42:698-714.

Bradford MM. A rapid and sensitive method for the quantitation of microgram quantities of protein utilizing the principle of protein dye binding. Anal Biochem. 1976;72:248254.

Chakraborty D, Samadder A, Dutta S, Khuda-Bukhsh AR. Antihyperglycemic potentials of a threatened plant, Helonias dioica: antioxidative stress responses and the signaling cascade. Exp Biol Med (Maywood). 2012;237:64-76.

Cheng YL, Lee SC, Lin SZ, Chang WL, Chen YL, Tsai NM, Liu YC, Tzao C, Yu DS, Harn HJ. Anti-proliferative activity of Bupleurum scrozonerifolium in A549 human lung cancer cells in vitro and in vivo. Cancer Lett. 2005;222:183-193.

Department of Health. Health and National Health Insurance Annual Statistics Information Service, Taiwan, 2009. Available at: http://www.nhi.gov.tw/English/webdata/webdata.aspx?menu $=11 \&$ menu_id=296\&webdata_id=1942\&WD_ID=296 (access ed on $01^{\text {st }}$ May 2013).

Ekambaram G, Rajendran P, Magesh V, Sakthisekaran D. Naringenin reduces tumor size and weight lost in N-methyl N'nitro-N-nitrosoguanidine-induced gastric carcinogenesis in rats. Nutr Res. 2008;28:106-112.

Es S, Kuttan G, Kc P, Kuttan R. Effect of homeopathic medicines on transplanted tumors in mice. Asian Pac J Cancer Prev. 2007;8:390-394.

Ferlay J, Shin HR, Bray F, Forman D, Mathers C, Parkin DM. 
Estimates of worldwide burden of cancer in 2008: GLOBOCAN 2008. Int J Cancer. 2010;127:2893-2917.

Fridovich I. Superoxide dismutase: An adaptation to a paramagnetic gas. J Biol Chem.1989;264:7761-7764.

Harvey RG. Polycyclic Aromatic Hydrocarbons. (New York, USA: Wiley-VCH), 1997

Henneke I, Greschus S, Savai R, Korfei M, Markart P, Mahavadi P, Schermuly RT, Wygrecka M, Stürzebecher J, Seeger W, Günther A. Ruppert C. Inhibition of urokinase activity reduces primary tumor growth and metastasis formation in a murine lung carcinoma model. Am J Respir Crit Care Med. 2010;181:611-619.

Hsu HF, Huang KH, Lu KJ, Chiou SJ, Yen JH, Chang CC, Houng JY. Typhonium blumei extract inhibits proliferation of human lung adenocarcinoma A549 cells via induction of cell cycle arrest and apoptosis. J Ethnopharmacol. 2011;135:492500.

Kamaraj S, Ramakrishnan G, Anandakumar P, Jagan S, Devaki T. Antioxidant and anticancer efficacy of hesperidin in benzo(a)pyrene induced lung carcinogenesis in mice. Invest New Drugs. 2009;27:214-222.

Kamaraj S, Vinodhkumar R, Anandakumar $\mathrm{P}$, Jagan $\mathrm{S}$, Ramakrishnan G, Devaki T. The effects of quercetin on antioxidant status and tumor markers in the lung and serum of mice treated with benzo(a)pyrene. Biol Pharm Bull. 2007;30:2268-2273.

Kassab S, Cummings M, Berkovitz S, van Haselen R, Fisher P. Homeopathic medicines for adverse effects of cancer treatments. Cochrane Database Syst Rev. 2009;15:1-44.

Kaur M, Agarwal C, Agarwal R. Anticancer and cancer chemopreventive potential of grape seed extract and other grape-based products. J Nutr. 2009;139:1806S-1812S.

Khuda-Bukhsh AR. Laboratory research in homeopathy: pro. Integr Cancer Ther. 2006;5:320-332.

Khuda-Bukhsh AR, Bhattacharyya SS, Paul S, Dutta S, Boujedaini N, Belon P. Modulation of Signal Proteins: A plausible mechanism to explain how a potentized drug Secale Cor 30C diluted beyond Avogadro's limit combats skin papilloma in mice. Evid Based Complement Alternat Med. 2011;2011:286320.

Kollinga A, Ernsta H, Rittinghausena S, Heinrich U, Pott F. Comparison of primary lung tumour incidences in the rat evaluated by the standard microscopy method and by multiple step sections. Exp Toxicol Pathol. 2008;60:281-288.

Kundu S, Sengupta S, Chatterjee S, Mitra S, Bhattacharyya A. Cadmium induces lung inflammation independent of lung cell proliferation: a molecular approach. J Inflamm (Lond).
2009;6:1-15.

Mallick P, Mallick JC, Guha B, Khuda-Bukhsh AR. Ameliorating effect of microdoses of a potentized homeopathic drug, Arsenicum Album, on arsenic-induced toxicity in mice. BMC Complement Altern Med. 2003;3:1-18.

Morin JE, Carmichael DF, Dixon JE. Characterization, kinetics and comparative properties of thiol: protein oxidoreductase. Arch Biochem Biophys.1978;189:354-363.

Pathak S, Kumar Das J, Jyoti Biswas S, Khuda-Bukhsh AR. Protective potentials of a potentized homeopathic drug Lycopdium-30, in ameliorating azo dye induced hepatocarcinogenesis in mice. Mol Cell Biochem. 2006;285:121-131.

Paul S, Bhattacharyya SS, Samaddar A, Boujedaini N, KhudaBukhsh AR. Anticancer potentials of root extract of Polygala senega against benzo[a]pyrene- induced lung cancer in mice. Zhong Xi Yi Jie He Xue Bao.2011;9:320-327.

Rice-Evans C, Burdon R. Free radical-lipid interactions and their pathological consequences. Prog Lipid Res. 1993;32:71110 .

Sikdar S, Mukherjee A, Boujedaini N, Khuda-Bukhsh AR. Ethanolic extract of Condurango (Marsdenia condurango) used in traditional systems of medicine including homeopathy against cancer can induce DNA damage and apoptosis in non small lung cancer cells, A549 and H522, in vitro. Tang. 2013;3:1-10

Stanton H, Rogerson FM, East CJ, Golub SB, Lawlor KE, Meeker CT, Little CB, Last K, Farmer PJ, Campbell IK, Fourie $\mathrm{AM}$, Fosang AJ. ADAMTS5 is the major aggrecanase in mouse cartilage in vivo and in vitro. Nature. 2005;434:648-652.

Sticha KR, Staretz ME, Wang M, Liang H, Kenney PM, Hecht SS. Effects of benzyl isothiocyanate and phenethyl isothiocyanate on benzo[a]pyrene metabolism and DNA adduct formation in the A/J mouse. Carcinogenesis. 2000;21:17111719.

Taraphdar AK, Roy M, Bhattacharya RK. Natural products as inducers of apoptosis: implication for cancer therapy and prevention. Curr Sci. 2001;80:1387-1396.

Yates JS, Mustian KM, Morrow GR, Gillies LJ, Padmanaban D, Atkins JN, Issell B, Kirshner JJ, Colman LK. Prevalence of complementary and alternative medicine use in cancer patients during treatment. Support Care Cancer. 2005;13:806-811.

Yeh CT and Yen GC. Effect of sulforaphane on metallothionein expression and induction of apoptosis in humanhepatoma HepG2 cells. Carcinogenesis. 2005;26:2138-2148. 